\section{Determination of Quadrupole and Spin-Rotation Coupling in the Rotational Spectrum of Carbonylsulfide- ${ }^{33} \mathrm{~S}$ and ${ }^{17} \mathrm{O}$}

\section{Ilona Merke and Helmut Dreizler}

Abteilung Chemische Physik im Institut für Physikalische Chemie der Universität Kiel

Z. Naturforsch. 42a, 1043-1044 (1987); received July 1, 1987

The quadrupole and spin rotation coupling constants are determined by analysis of the $J=0-1$ and $J=1-2$ transitions of $\mathrm{OC}^{33} \mathrm{~S}$ and ${ }^{17} \mathrm{OCS}$ in natural abundance. The data are compared with those obtained from molecular beam electric resonance and very recent pulsed beam microwave Fourier transform spectroscopy.

In the past several years we have contributed to the development of microwave Fourier transform (MWFT) spectroscopy [1-5] of static molecular gases in thermodynamic equilibrium as a spectroscopic tool with high resolution and sensitivity. For critical evaluation of its limits, it is necessary to compare results gained with static gas MWFT spectroscopy with those from spectroscopic methods with inherently higher resolution. We present a comparison with the hyperfine structure (hfs) of carbonylsulfide- ${ }^{33} \mathrm{~S}, \mathrm{OC}^{33} \mathrm{~S}$, and carbonylsulfide- ${ }^{17} \mathrm{O}$, ${ }^{17}$ OCS. Reinartz and Dymanus [6] determined the nuclear quadrupole coupling constant eq $Q$ and the spin rotation constant $C_{I}$ with molecular beam electric resonance spectroscopy from the $J=0-1$ transition in the $v_{2}=0$ and $v_{2}=1$ vibrational states. Very recently Lovas and Suenram [7] investigated both isotopic species with a pulsed beam MWFT spectrometer with $1 \%$ OCS in Argon. Their values for the $J=0-1$ transitions are reproduced in Tables 1 and 2 . We investigated the $J=0-1$ and $1-2$ transitions. We measured the hfs of both isotopes in natural abundance $\left(0.75 \%\right.$ for ${ }^{33} \mathrm{~S}$ and $0.04 \%$ for ${ }^{17} \mathrm{O}$ ). The frequencies are given in Table 1 . For ${ }^{17} \mathrm{OCS}$ the line frequencies were corrected with a line shape analysis [8]. Figure 1 provides a representative measurement. For $\mathrm{OC}{ }^{33} \mathrm{~S}$ it was not necessary because the triplet is widely split. For $\mathrm{OC}^{33} \mathrm{~S}$ we succeeded to measure the $J=2-3$ line with a new MWFT-spectrometer [9]. As the quality of the spectra is not yet comparable with those of lower frequency ranges, the components of the line were not included in the fit. The hfs was analysed according to $[10,11]$.

Reprint requests to Prof. Dr. Helmut Dreizler, Institut für Physikalische Chemie, Universität Kiel, Olshausenstr. 40, D-2300 Kiel.
Table 1. Quadrupole hyperfine structure of rotational transitions of carbonylsulfide ${ }^{33} \mathrm{~S}$ and ${ }^{17} \mathrm{O} . \quad v$ : measured frequencies [MHz], $\Delta v_{\mathrm{hfs}}$ : splittings referred to the hypothetical unsplit line $[\mathrm{MHz}], \delta=\Delta v_{\mathrm{hfs}}-\Delta v_{\text {calc }}, \Delta v_{\text {calc }}$ : splittings calculated with the constants of Table 2 . Components of $J=2-3$ not included in the fit.

\begin{tabular}{|c|c|c|c|c|c|}
\hline $\begin{array}{l}\mathrm{OC}^{33} \mathrm{~S} \\
J-J^{\prime}\end{array}$ & $F-F^{\prime}$ & $v$ & $\Delta v_{\mathrm{hfs}}$ & $\delta$ & $v[7]$ \\
\hline $0-1$ & $\begin{array}{l}3 / 2-1 / 2 \\
3 / 2-5 / 2 \\
3 / 2-3 / 2\end{array}$ & $\begin{array}{l}12017.105 \\
12011.285 \\
12004.002\end{array}$ & $\begin{array}{r}7.279 \\
1.458 \\
-5.824\end{array}$ & $\begin{array}{l}0 \\
0 \\
0\end{array}$ & $\begin{array}{l}12017.101(8) \\
12011.287(4) \\
12003.998(4)\end{array}$ \\
\hline $1-2$ & 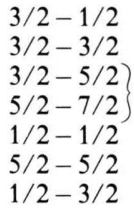 & $\begin{array}{l}24032.725 \\
24025.448 \\
24020.249\end{array}$ & $\begin{array}{r}13.101 \\
5.824 \\
0.625 \\
0.001 \\
-6.660 \\
-7.279\end{array}$ & $\begin{array}{r}0 \\
0 \\
0 \\
-1 \\
3 \\
-2 \\
0\end{array}$ & \\
\hline${ }^{17} \mathrm{OCS}$ & $\left.\begin{array}{l}3 / 2-3 / 2 \\
5 / 2-5 / 2 \\
7 / 2-9 / 2 \\
5 / 2-7 / 2 \\
1 / 2-3 / 2 \\
3 / 2-5 / 2 \\
3 / 2-3 / 2\end{array}\right\}$ & $\begin{array}{l}36027.900 \\
36022.448\end{array}$ & $\begin{array}{r}5.796 \\
3.757 \\
0.346 \\
-1.466 \\
-6.918\end{array}$ & $\begin{array}{r}-23 \\
15 \\
-2 \\
-1 \\
-8 \\
-8 \\
19\end{array}$ & \\
\hline $0-1$ & $\begin{array}{l}5 / 2-3 / 2 \\
5 / 2-7 / 2 \\
5 / 2-5 / 2\end{array}$ & $\begin{array}{l}11767.532 \\
11767.400 \\
11767.132\end{array}$ & $\begin{array}{r}0.193 \\
0.061 \\
-0.207\end{array}$ & $\begin{array}{r}-5 \\
2 \\
3\end{array}$ & $\begin{array}{l}11767.531(6) \\
11767.402(6) \\
11767.135(4)\end{array}$ \\
\hline $1-2$ & $\begin{array}{l}5 / 2-3 / 2 \\
5 / 2-5 / 2 \\
5 / 2-7 / 2 \\
7 / 2-9 / 2 \\
3 / 2-3 / 2 \\
7 / 2-7 / 2 \\
3 / 2-5 / 2\end{array}$ & $\begin{array}{l}23534.976 \\
23534.774 \\
23534.678 \\
23534.557 \\
23534.427 \\
23534.364\end{array}$ & $\begin{array}{r}0.329 \\
0.127 \\
0.031 \\
-0.090 \\
-0.220 \\
-0.283\end{array}$ & $\begin{array}{r}6 \\
2 \\
-16 \\
10 \\
-5 \\
2 \\
0\end{array}$ & \\
\hline
\end{tabular}

Table $2 .{ }^{33} \mathrm{~S}$ and ${ }^{17} \mathrm{O}$ quadrupole coupling $e Q q$ and spin rotation constant $C_{I}$ of $\mathrm{OC}^{33} \mathrm{~S}$ and ${ }^{17} \mathrm{OCS}$ in the vibrational ground state. Standard error in units of the last digit in brackets. - not determined

\begin{tabular}{llll}
\hline & $\begin{array}{l}e q \\
{[\mathrm{MHz}]}\end{array}$ & $\begin{array}{l}C_{I} \\
{[\mathrm{kHz}]}\end{array}$ & Ref. \\
\hline $\mathrm{OC}^{33} \mathrm{~S}$ & $-29.1184(12)$ & $0.87(5)$ & {$[6]$} \\
& $-29.11(4)$ & - & {$[7]$} \\
& $-29.122(3)$ & $1.1(4)$ & this work \\
${ }^{17} \mathrm{OCS}$ & $-1.30(3)$ & - & {$[7]$} \\
& $-1.333(22)$ & $-3.3(13)$ & this work \\
\hline
\end{tabular}

From the data it is clearly seen that the beam electric resonance method is superior in precision. The data agree roughly in one standard error. Both MWFT methods appear equivalent in this application. Experience indicates that MWFT spectroscopy is applicable to a greater variety of molecules, especially to larger ones.

0932-0784/ $87 / 0900-1043 \$ 01.30 / 0$. - Please order a reprint rather than making your own copy. 


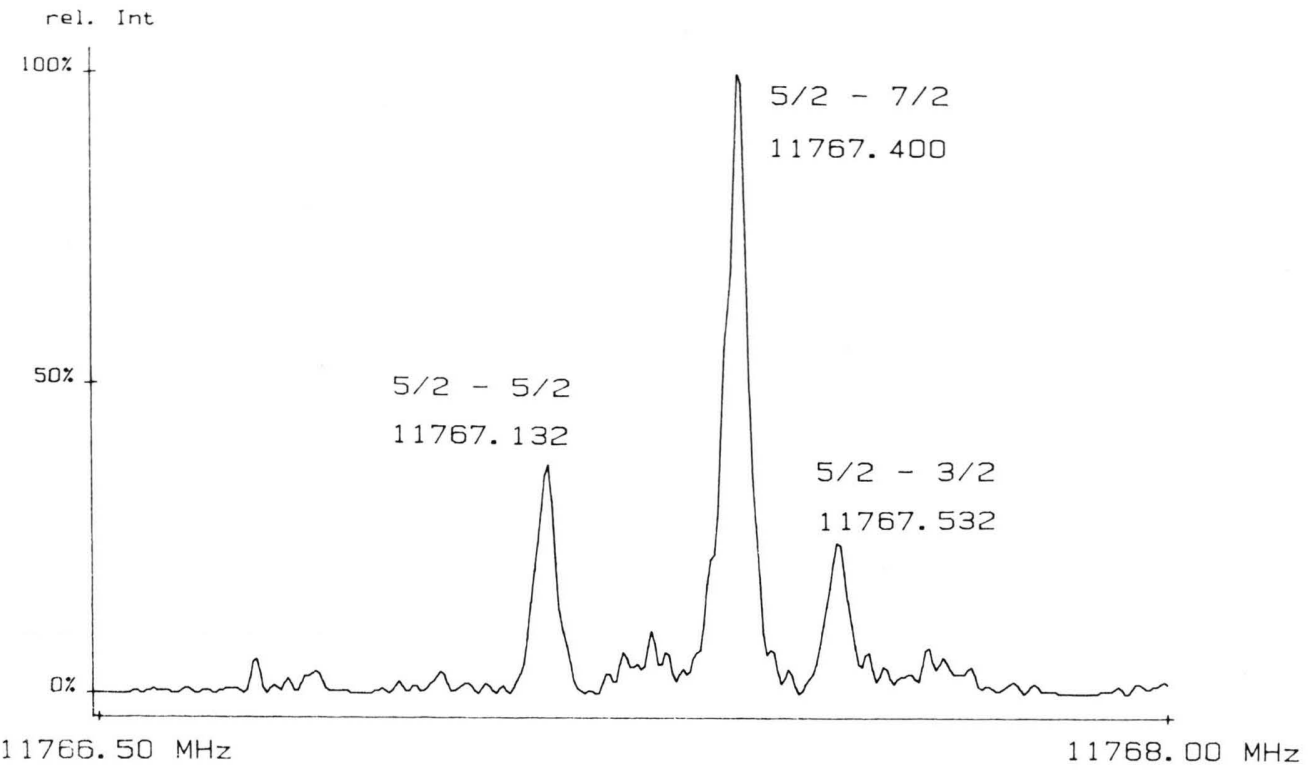

Fig. 1. Rotational transition $J=1-0$ of carbonylsulfide- ${ }^{17} \mathrm{O},{ }^{17} \mathrm{OCS}$, showing ${ }^{17} \mathrm{O}$-hfs. Polarisation frequency $11768.000 \mathrm{MHz}$, temperature $-30^{\circ} \mathrm{C}$, pressure $1.9 \mathrm{mTorr}(0.25 \mathrm{~Pa}), 4 \cdot 10^{7}$ averaging cylces, 1024 data points supplementend by 3072 zeros prior to Fourier transformation, sampling interval $50 \mathrm{~ns}$.

We thank the members of our group for help and discussions, Dr. F. J. Lovas and Dr. R. D. Suenram, NBS, Washington, for the permission to use their data prior to

[1] H. Dreizler, Mol. Phys. 59, 1, (1986).

[2] G. Bestmann, H. Dreizler, H. Mäder, and U. Andresen, Z. Naturforsch. 35a, 392 (1980).

[3] G. Bestmann and H. Dreizler, Z. Naturforsch. 37a, 58 (1982).

[4] G. Bestmann, H. Dreizler, E. Fliege, and W. Stahl, J. Mol. Struct. 97, 229 (1983).

[5] W. Stahl, G. Bestmann, H. Dreizler, U. Andresen, and R. Schwarz, Rev. Sci. Instrum. 56, 1759 (1985). publication, Dr. F. J. Lovas for critical comments, the Deutsche Forschungsgemeinschaft, the Fonds der Chemie and the Land Schleswig-Holstein for funds.

[6] J. M. L. J. Reinartz and A. Dymanus, Chem. Phys. Lett. 24, 346 (1974).

[7] F. J. Lovas and R. D. Suenram, to be published.

[8] I. Merke, Diplomthesis, Kiel 1986.

[9] H. Dreizler, U. Andresen, J. Gripp, I. Merke, M. Meyer, W. Stahl, R. Schwarz, and K. Vormann, Z. Naturforsch. to be published.

[10] W. Gordy and R. L. Cook, Microwave Molecular Spectra 3rd Ed., Interscience Publishers, New York 1984, p. 408.

[11] 1.c. 10, p. 432. 